\title{
Radiation Exposure to the Patient During Diagnostic Coronary Angiogram at Dhulikhel Hospital.
}

\section{Humagain $\mathrm{S},{ }^{1}$ Maharjan $\mathrm{R}^{2}{ }^{2}$ Koju $\mathrm{R}^{1}$}

\author{
Corresponding Author \\ Sanjaya Humagain \\ Department of Cardiology \\ Dhulikhel Hospital, Kathmandu University Hospital \\ Dhulikhel, Kavre \\ E-mail: sanjayahumagain@hotmail.com
}

\section{Citation}

Humagain S, Maharjan R, Koju R. Radiation Exposure to the Patient During Diagnostic Coronary Angiogram at Dhulikhel Hospital. Kathmandu Univ Med J 2015;49(1):61-3.

\begin{abstract}
Background

Radiation is a necessary evil in Coronary Angiogram. The Interventional Cardiology procedure provides huge benefit to the patient but at the cost of radiation. There is evidence of cumulative effect of radiation. Therefore it is essential to keep the radiation dose as minimum as possible.
\end{abstract}

\section{Objective}

The aim of this study is to find out radiation exposed to the patient undergoing diagnostic coronary angiogram.

\section{Method}

A retrospective study was done. Those patients who underwent diagnostic coronary angiogram were selected for the study. There were total of 166 patients. Radiation exposure in terms of fluoroscopy time in minute and dose area product (DAP) in Gy.cm2 was recorded.

\section{Result}

Out 166 patients 92 were male and 74 female. Age range was from 39 to 79 years with mean age $58.13 \pm 9.14$. Amount of contrast used was in range of 30 to $100 \mathrm{ml}$ with mean of $45.54 \pm 14.06$. Range of fluoroscopy time was 2.60 to 37.00 minutes with mean $11.38 \pm 6.80$. Mean fluoroscopy time in male was $10.92 \pm 5.82$ minutes and in females it was $11.92 \pm 7.68$ minutes, with $p 0.331$. The range of DAP was 11.00 Gy.cm2 to $106.00 \mathrm{~Gy} . \mathrm{cm} 2$ with mean $40.73 \pm 23.58 \mathrm{~Gy} . \mathrm{cm} 2$. The mean DAP in male and female was $38.77 \pm 23.26$ Gy.cm2 and $43.16 \pm 23.90$ Gy.cm2 respectively with $p$ 0.234 .

\section{Conclusion}

From this study we can conclude that the radiation exposure to our patient undergoing coronary angiogram is similar to the international values in terms DAP but more in terms of fluoroscopy time. When males and females compared there is no difference.

\section{KEY WORDS}

Coronary angiogram, dose area product (DAP), fluoroscopy time, radiation. 


\section{INTRODUCTION}

Radiation is a necessary evil in Coronary Angiogram (CA). The growing use of Interventional Cardiology (IC) procedures offers huge benefits to patients but at the same time contributes significantly to the radiation exposure. ${ }^{1-3}$ Nonetheless, many cardiologists are unaware that they may be exposing patients to relatively high levels of radiation. Same patient may undergo radiation exposure for different indication at different time and there is an evidence of cumulative effect. Therefore, it is essential to reduce the radiation dose as far as possible. CA is now done at regular basis at different centers in Nepal but no data regarding the radiation exposure to the patients is available.

Dhulikhel Hospital has a cardiovascular laboratory with Integris Phillips H5000S, Phillips Medical System which measures radiation exposure in terms of fluoroscopy time in minutes and dose area product (DAP) expressed as gray centimeter square (Gy.cm2). Fluoroscopy time (usually measured in minutes) is a non-dosimetric quantity; however it is widely used to since it is readily available and still the only method routinely employed in many interventional laboratories. ${ }^{4}$ Dose Area Product (DAP), which is measured in Gy.cm2, is the product of the dose in air in a given plane by the area of the irradiating beam and is independent of the distance from the $x$-ray source because the decrease in dose with distance parallels the increase in area. ${ }^{4}$

This study is designed to find out the radiation exposure to the patient. This information can be useful to the clinicians as well as the patients.

\section{METHODS}

This is a retrospective study. The patient report record kept at Dhulikhel Hospital Cathlab was collected and those patient who underwent diagnostic coronary angiogram from April 2012 to December 2014 were selected for the study. There were total of 166 patients. Demographic profiles age and sex was recorded. Radiation exposure in terms of fluoroscopy time in minute and dose area product (DAP) in Gy.cm2 was recorded.

Any patient who underwent percutaneous coronary angioplasty $(\mathrm{PCl})$, other procedure and when any data was missing were excluded from the study.

Dhulikhel Hospital has a cardiovascular laboratory with Integris Phillips H5000S. Procedure is performed by the two cardiologists present at the hospital.

Statistical analysis is done using SPSS 17. Independent t-test was applied wherever applicable.

\section{RESULTS}

Out of total 166 patients 92 were male and 74 were female. Age range was from 39 to 79 years with mean age
58.13 \pm 9.14 . Distribution of patient according to different age group and gender is given in Figure 1.

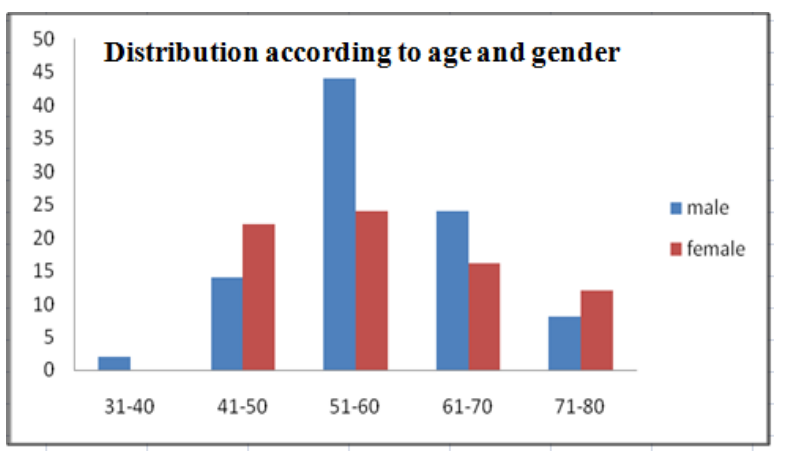

Figure 1. Distribution of patient according to age and gender.

The amount of contrast used was in range of 30 to $100 \mathrm{ml}$ with mean of $45.54 \pm 14.06$. The mean amount of contrast used was $45.76 \pm 13.09$ and $45.27 \pm 15.26$ in male and female respectively (Figure 2 ).

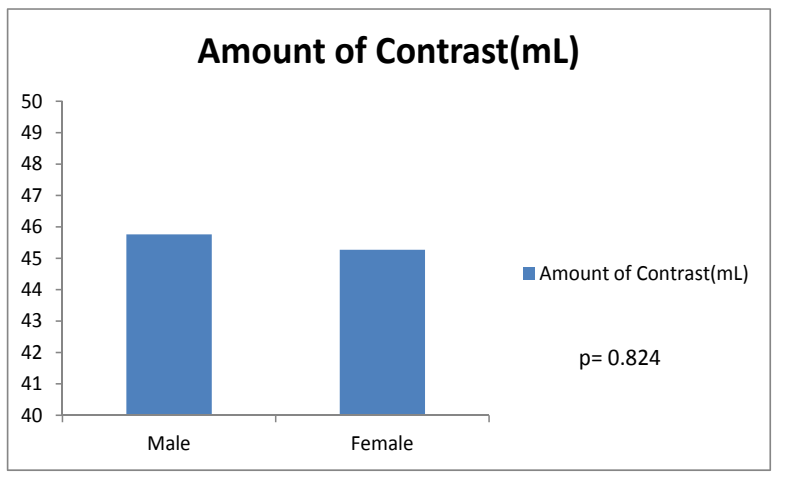

Figure 2. Distribution of patient according to gender and amount of contrast.

The minimum and the maximum fluoroscopy time were 2.60 and 37.00 minutes respectively with mean $11.38 \pm$ 6.80 minutes. The mean fluoroscopy time in male was $10.92 \pm 5.82$ and in females it was $11.92 \pm 7.68$, however there is no statistically significant difference, $\mathrm{p}$ being 0.331 . The minimum DAP was $11.00 \mathrm{~Gy} . \mathrm{cm} 2$ and the maximum 106.00 Gy.cm2. Mean DAP was $40.73 \pm 23.58 \mathrm{~Gy} . \mathrm{cm} 2$. The mean DAP in male and female was $38.77 \pm 23.26$ Gy.cm2 and $43.16 \pm 23.90$ Gy.cm2 respectively (Table 1 ).

Table 1. Distribution of patient according to gender and radiation.

\begin{tabular}{|lccc} 
& & $\begin{array}{c}\text { Fluoroscopy time / min } \\
\text { Mean (range) }\end{array}$ & $\begin{array}{c}\text { Dose Area product/ Gy.cm2 } \\
\text { Mean (range) }\end{array}$ \\
\hline Male & 92 & $10.92 \pm 5.82(3.00-30.00)$ & $38.77 \pm 23.26(11.00-106.00)$ \\
\hline Female & 74 & $11.96 \pm 7.86(2.60-37.00)$ & $43.16 \pm 23.90(12.00-99.00)$ \\
\hline Total & 166 & $11.38 \pm 6.80(2.60-37.00)$ & $40.73 \pm 23.58(11.00-106.00)$ \\
& & $p=0.331$ & $p=0.234$
\end{tabular}




\section{DISCUSSION}

With increasing number and complexities of procedure, there has been a lot of concern regarding radiation to the patients and the cathlab operating staffs. A high value of radiation exposure is a necessary consequence in coronary angiogram. Though, radiation exposure was not given priority in early days of invasive cardiology and there was no standard way of measurement, radiation exposure during the procedure has been one of the important concerns of the health care individuals in present day.

The average DAP for one chest $x$-ray is 0.12 Gy.cm2, for $\mathrm{x}$-ray abdomen is $3.1 \mathrm{~Gy} . \mathrm{cm} 2$, for Barium enema it is 47.0 Gy.cm2, for Barium meal 17.0 Gy.cm2, for ERCP it is 19.0 $\mathrm{cm} 2$, for IVU 12.0 Gy.cm2. ${ }^{5}$

In one of the study done in Greece the median fluoroscopy time was 5.00 min which is better than ours. ${ }^{6}$ However, the value for $\mathrm{DAP}^{7}$ was found to be similar to our findings. In other study also, median fluoroscopy time was $6.3 \mathrm{~min}$ and median DAP 63 Gy.cm 2. ${ }^{7}$ This disparity may be due to the reason that they have included those cases which were performed by the experienced cardiologists whereas, in our study even the first case was included.
Balter et al collected DAP value for 2265 CAG done at seven different centers and found that it ranged from 5.00 to 130 Gy.cm2, which is similar to our study. ${ }^{8}$ The average fluoroscopy time for coronary angiogram was 6.2 min before 2000 and $3.7 \mathrm{~min}$ after 2000 . The average DAP 52.5 Gy.cm2 was before 2000 and $31.1 \mathrm{~Gy} . \mathrm{cm} 2$ after $2000 .^{9}$ While comparing with fluoroscopy time, ours was found to be longer however DAP value are similar.

In the present study, analyzing the radiation exposure time in male and female did not show any difference. To the best of my knowledge, we couldn't find such comparison done till now. Though, we suggest performing this comparison in large population for the definitive result. In addition, multicentered study should be conducted.

\section{CONCLUSION}

From this study, we can conclude that the radiation exposure to our patient undergoing CAG in our centre is similar to the internationally accepted values in terms of DAP. However, it is important for the interventional cardiologist to be aware of radiation exposure to the patients while performing procedure and also keep it to as minimum level as possible.

\section{REFERENCES}

1. Neofotistou V, Vano E, Padovani R, Kotre J, Dowling A, Toivonen M, et al. Preliminary reference levels in interventional cardiology. Eur Radiology. 2003; 13(10): 2259-63.

2. Benini $A$, Pedersen $F$, Jorgensen $E$. Doses to patients in interventional cardiology. IFMBE Proceedings. 2009.

3. Herrmann HC, Baxter S, Ruiz CE, Feldman TE, Hijazi ZM. SCAI Council on Structural Heart Disease. Results of the society of cardiac angiography and interventions survey of physicians and training directors on procedures for structural and valvular heart disease. Catheter Cardiovasc Interv. 2010; 76(4): 106-10.

4. Einstein AJ, Moser KW, Thompson RC, Cerqueira MD, Henzlova MJ. Radiation dose to patients from cardiac diagnostic imaging. Circulation. 2007; 116: 1290-305.

5. Johnson DA, Brennan PC. Reference dose levels for patients undergoing common diagnostic examinations in Irish Hospitals. Brit. J. Radiol 2000;73:396-402.

6. Tsapaki V, Kottou S, Vano E, Faulkner K, Giannouleas J, Padovani R, et al. Patient dose values in a dedicated Greek cardiac centre. $\mathrm{Br} J$ Radiol. 2003; 76(910): 726-30.

7. Georges JL, Livarek B, Gibault-Genty G, Messaoudi H, Aziza JP, Hautecoeur JL, et al. Variations of radiation dosage delivered to patients undergoing interventional cardiological procedures. A monocentric study 2002-05. Arch Mal Coeur Vaiss. 2007;100(3): 175-81.

8. Balter S, Miller DL, Vano E, et al. A pilot study exploring the possibility of establishing guidance levels in $\mathrm{x}$-ray directed interventional procedures. Med Phys. 2008; 35: 673-80.

9. Pantos I, Patatoukas G,. Katritsis DG, Efstathopoulos E. Patient Radiation Doses in Interventional Cardiology Procedures. Current Cardiology Reviews. 2009; 5: 1-11. 